\title{
From Here to Ephemerality: Fugitive Sources in Libraries, Archives, and Museums: The 48th Annual RBMS Preconference
}

FOR TOO LONG, institutions have treated their collections of ephemera as impediments rather than assets. They considered that ephemera had intrinsically less research value than books or manuscripts, that it was difficult to store and access, and that it often came in collections so large and unwieldy that they would never be adequately cataloged or inventoried. Vast troves of broadsides, handbills, and circulars languished unsorted in boxes, and the existence of these collections was seldom advertised to potential researchers, and sometimes carefully hidden from them. And yet some scholars took strong interest in these types of materials, some collectors and dealers amassed large collections, and some of the more prescient institutions also took the lead in collecting and caring for ephemera. It would be too soon to declare that we have entered the age of ephemera in our institutions, but it would certainly be true to say that there is now greater interest in these artifacts of everyday life than ever before.

As a sign of this increasing awareness of ephemera in our collections, ephemera was the theme of the 48th Annual RBMS Preconference held in Baltimore from June 19 to June 22, 2007. It was the first time that RBMS devoted an entire preconference to this topic, and the preconference drew the largest attendance of any RBMS preconference to date. The program consisted of six plenary sessions, twelve short papers, and nine seminars exploring different aspects of ephemera in libraries, museums, and archives. In addition, the program included two workshops, one on organizing and cataloging ephemera, and the other on fundraising for libraries. The unprecedented success of the preconference was due to its compelling theme, to its location in Baltimore (a city never before visited by RBMS), and to the work of the Program Committee, of the Seminars Committee, and of the outstanding Local Arrangements Committee headed by Cynthia Requardt, Curator of Special Collections at Johns Hopkins University.

Michael Twyman's keynote address, “The Long-Term Significance of Printed Ephemera," highlighted the importance of ephemera not just to social historians, 
but also to historians of printing, who must study the full range of printed materials to gain an understanding of the techniques and innovations that were sometimes first introduced in the printing of ephemera. In his paper, Twyman argued that examples of ephemera provide evidence that is seldom found in other types of printed materials and that furthers our understanding of a particular event or time period. He emphasized that, without a look at printed ephemera, one's understanding of graphic design and printing history would be severely limited.

Jon Solomon, in a thrilling multimedia presentation during the second plenary session, demonstrated how eBay has allowed him to reconstruct the extraordinary marketing phenomenon that surrounded Lew Wallace's Ben-Hur after its publication in 1880. His article, entitled "Fugitive Sources, Ben-Hur, and the Popular Art 'Property," argues that Ben-Hur was the first example of a popular best-seller to cross over into the commercial world, and that ephemera found on eBay provide a window into a moment in popular culture and consumerism that would otherwise be little remembered today.

The value of ephemera as primary source material was further developed during the second plenary session by Cheryl Ganz, in her presentation entitled "Fan Dancing and Fan Belts: Selling Optimism at the 1933 Chicago World's Fair.” In her talk and in the article published in this journal, Ganz argues that the large quantity of ephemera occasioned by the Chicago World's Fair provides the historian with a fuller understanding of the contents and organization of the fair and its impact on visitors and offers tangible evidence of a shift from world's fairs that emphasized individual entrepreneurship to those that celebrated corporate capitalism and the idea of progress through scientific and technological innovation.

The third plenary session consisted of a panel of ephemera dealers, Diane DeBlois and Robert Dalton Harris of aGatherin', and David Margolis and Jean Moss of Margolis and Moss. They gave a fascinating presentation, based on their personal experiences in the ephemera trade, about the importance of dealers, who play a crucial role in the life cycle of ephemera by acquiring, organizing, describing, and adding value to the ephemera they find and offer to libraries and collectors. Their personal reflections on the ephemera trade in relation to special collections are presented here in the article entitled "The Contribution of Ephemera Dealers."

During the fourth plenary session, two collectors spoke about different aspects of collecting ephemera. William H. Helfand, in his talk on "Ephemeral Guides for the Medically Perplexed," described how the twentieth-century street guides in his collection were originally used as vehicles for advertising sexual remedies and medical services for men and reveal much about men's anxieties with regard to their sexual health. William J. Barlow, in his paper entitled "Spinning Straw into Gold: Gilding 
Junk through Collecting," which appears in this issue of RBM, further explored the notion of added value introduced in the dealers' panel. His extensive collection of Duncan Hines ephemera and other memorabilia from the 1930s to the 1950s illustrates the role of collectors who contribute their time, expertise, and connoisseurship to create collections that have lasting scholarly and aesthetic importance.

The fifth plenary session was devoted to different aspects of the management of ephemera collections in institutions. In her paper entitled "Why Not Ephemera? The Emergence of Ephemera in Libraries," published here, Georgia B. Barnhill presented a survey of how changing attitudes in libraries are making ephemera collections more accessible to scholars. She provided an overview of recent scholarly publications that have made extensive use of ephemera, and described how institutions such as the Library Company of Philadelphia, Emory University, the Hagley Museum and Library, and the American Antiquarian Society are making their collections of ephemera better known and accessible through cataloging, digitization, exhibitions, and scholarly programs. The fifth plenary session also included a presentation from Nicolas Ricketts, who discussed the museum curator's perspective in his talk, "The Truth Is in the Details: Ephemera in Museum Collections and Exhibitions," and described his work with ephemera at the Strong National Museum of Play. John Pull of the Library of Congress, in his presentation entitled "Fugitive Bytes: Ephemera’s Digital Horizons," spoke about extending the concept of ephemera in libraries to encompass "born digital" materials, or risk the loss of much of the ephemera that is being produced today. He offered the intriguing insight that ephemera especially appeals to us because we too are ephemeral.

The twelve short papers presented at the preconference were grouped into four sessions that explored different aspects of the conference theme. These included "Into the Classroom"; "Window into History and Culture"; "Collecting and Its Varieties"; and "Access Issues." Four among the short papers were selected for this issue of RBM. Barbara Heritage, in her article entitled "The Shapes Jane Eyre Takes: Ephemeral Responses to the Book and Its Themes," argues that the profusion of memorabilia and ephemera surrounding the novel reveals personal responses that add to our understanding of the text and its many manifestations. In their article on "Teaching with Ephemera," Julia Gardner and David Pavelich discuss their efforts to include ephemera as part of the special collections used in classroom instruction at the University of Chicago and explain the particular way in which ephemera can illuminate a topic for students, give them a broader understanding of the subject, reinforce their critical thinking skills, and allow them to engage in more meaningful classroom discussions. Jill Gage, in her article entitled "With Deft Knife and Paste: The Extra-Illustrated Books of John M. Wing," offers a fascinating look at an individual who created an astonishing monument to himself as printer, illustrator, 
collector, and benefactor, by extra-illustrating over 350 volumes now preserved at the Newberry Library. Gregory J. Prickman’s "A Network and Its Ephemera before the Internet: The Hidden Treasures and Clear Challenges of Apazines" provides a window into a subculture of science fiction fans who produced large amounts of ephemeral materials that have increasing research value for institutions that preserve them and try to make them accessible.

The plenary sessions took preconference attendees through a tour of the life-cycle of ephemera, from the importance and value of ephemera collections, to the role of dealers and collectors in building these collections, to the management of ephemera in libraries and museums. In her conference wrap-up during the sixth plenary session, entitled "Immortalizing the Mayfly. Permanent Ephemera: an Illusion or a (Virtual) Reality?," Julie Anne Lambert provided a summary of the themes covered in short papers, seminars, and plenaries, illustrated with examples from her work as the curator of the John Johnson Collection at the Bodleian Library. She placed particular emphasis on the importance of thoroughly cataloging and digitizing ephemera, concerns that were echoed in many other presentations at the preconference.

Attendees came away from the preconference with a greater understanding of the topic of ephemera. They heard about the importance of ephemera as primary source material that provides context for a historical period. They learned that the study of printing history would be incomplete without taking ephemera into consideration. They heard from dealers and collectors of ephemera who argued that their role is especially crucial in building collections of these materials for institutions. The relatively recent role of eBay in developing collections and opening up new avenues of scholarship was a frequent refrain in presentations. Attendees also heard about the infinite variety of ephemera and about the special concerns of institutions that maintain these collections, from preservation issues, to the need for cataloging, to the desirability of digitizing ephemera collections to make them better known and better accessible. They also heard about exhibitions based on ephemera, which bring a particular topic or time period to life with an immediacy that has particular appeal to visitors.

One constant theme throughout the preconference was the need for better access to these hidden collections, many of which are still marginalized by institutions. Indeed, ephemera often exists on the margins, created outside the mainstream of book and periodical publishing, treated as peripheral by special collections that focus chiefly on manuscripts and rare books as the principal primary sources for research, and revealing the voices of individuals who are themselves on the margins of society. Scholars and collectors discovered the world of ephemera some time ago; but, as the Baltimore preconference made clear, it is now time for libraries to embrace these materials fully and bring them into the mainstream. 


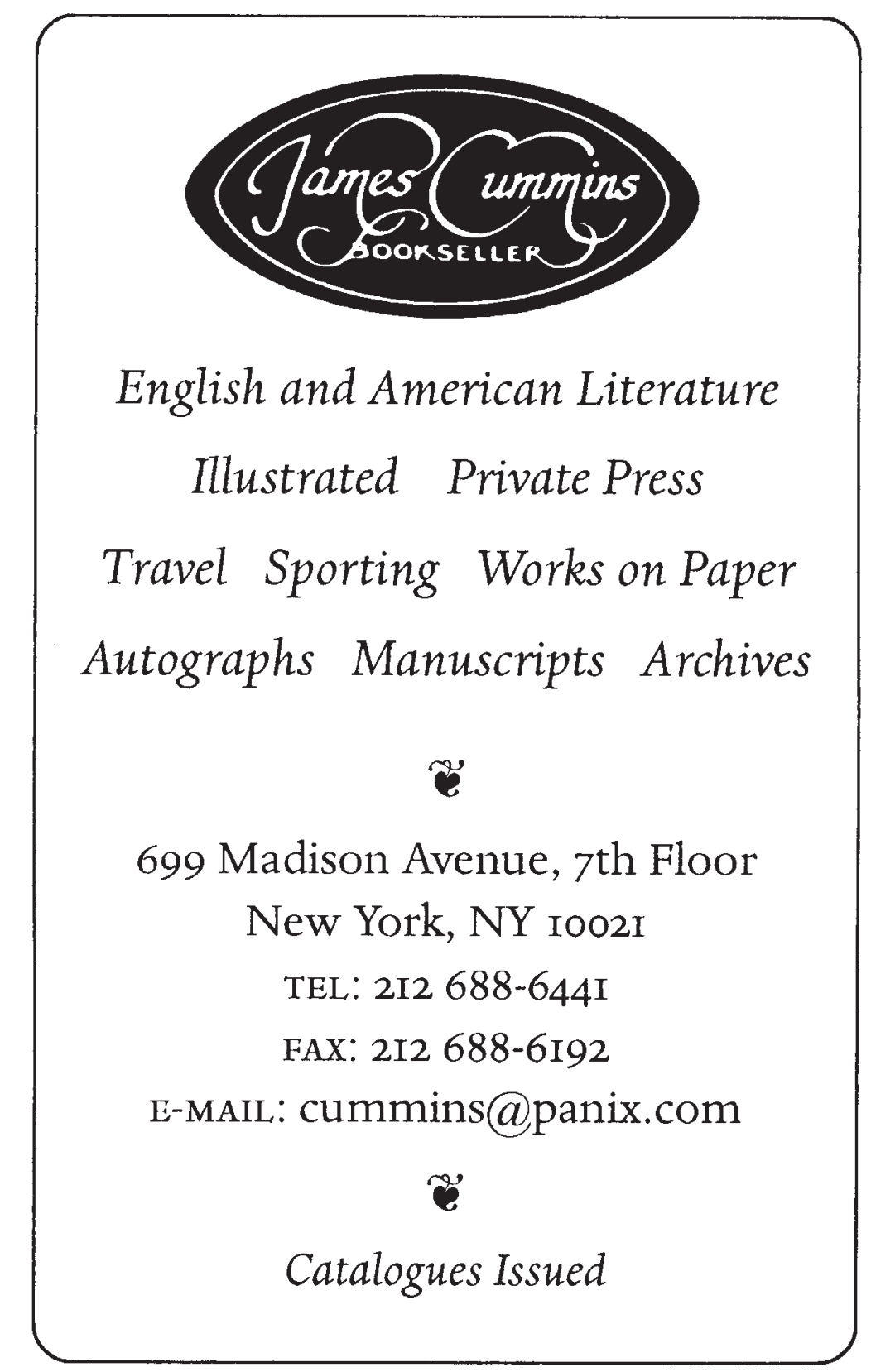

